\title{
ANALISA KEPUTUSAN PEMBELIAN SECARA ONLINE KOPI ANDANAN
}

\author{
DANDI SETIAWAN ${ }^{1}$, AGUS PURNOMO ${ }^{2}$ \\ ${ }^{1}$ Mahasiswa Jurusan Administrasi Bisnis, Universitas Bandar Lampung \\ ${ }^{2}$ Dosen Pembimbing Program Studi Administrasi Bisnis, Universitas Bandar Lampung \\ Jl. Zainal Abidin Pagar Alam No.26, Labuhan Ratu, Kedaton, 35142, Bandar Lampung \\ Indonesia \\ agus.purnomo@ubl.ac.id \\ dandi.17121013@student.ubl.ac.id
}

\begin{abstract}
Abstrak
Penelitian yang saya gambarkan ini bertujuan untuk mengetahui pengaruh promosi, harga, kepercayaan dan kemudahan terhadap keputusan pembelian secara online kopi andanan. Manfaat dari riset ini secara toritis diharapkan dapat memberi sumbangan baru terhadap pengetahuan, khususnya terkait dengan kewirausahaan, sebaliknya secara instan diharapkan sanggup jadi bahan masukan untuk keberlangsungan kemajuan usaha kopi andanan. Metodologi yang digunakan dalam riset ini adalah penulisan skripsi kuantitatif. Hasil yang didapat dari riset ini meyakinkan kalau factor yang sangat dominan mempengaruhi terhadap keputusan pembelian secara online merupakan Kemudahan. Ini sebabkan produk yang idamkan serta diperlukan konsumen sangat mudah proses pembeliannya/pemesanannya.
\end{abstract}

Kata Kunci : Penjualan; Promosi; Kewirausahaan; Kemudahan; Online.

\section{PENDAHULUAN}

Berkembangnya teknologi sekarang ini sangat berakibat pada pertumbuhan sosial, budaya serta ekonomi secara signifikan. Internet merupakan contoh pertumbuhan teknologi informasi serta komunikasi pada sekarang ini. Internet bisa menghasilkan suatu wadah ekonomi baru yang memunculkan sebuah aspek kehidupan, terdapat pula pertumbuhan bisnis serta pemasaran. Warga banyak melakukan pemasaran serta bisnis dengan menggunakan jangkauan internet 
yang luas. Banyak yang berfikir apabila melakukan pemasaran suatu bisnis lewat internet akan mendapat lebih banyak keuntungan baik untuk perseorangan, industri maupun konsumen.

Dengan terus meningkatnya jumlah pengguna internet, banyak pembisnis yang menargetkan pemasaran lewat internet mempunyai sasaran pasar yang sangat potensial. Perihal ini hendak membuat praktek penjualan secara online bisa mempunyai banyak keuntungan untuk industri ataupun konsumen. (Rian Sasmita, 2013)

\section{TINJAUAN PUSTAKA}

\section{Pemasaran}

Pemasaran ialah aktivitas mempertahankan kelangsungan hidup sesuatu usaha baik itu industri di bidang jasa ataupun benda. Perihal tersebut diakibatkan sebab pemasaran ialah salah satu aktivitas industri. Definisi pemasaran berarti bekerja dengan pasar target, mewujudkan nilai pertukaran yang potensial. Bisa dikatakan kalau keberhasilan dalam sesuatu usaha dalam bidang pemasaran ialah kunci kesuksesan dari sesuatu usaha tersebut (Philip Kotler 2008).

Pemasaran merupakan sesuatu sistem keseleruhan kegiatan bisnis yang diperuntukan untuk mengatur, memastikan harga, promosi serta pendistribusian barang ataupun jasa yang memuaskan pembeli yang ada ataupun pembeli potensial (Stanton, 2004).

\section{METODOLOGI PENELITIAN}

\section{Jenis penelitian}

Penelitian ini menggunakan penilitian kuantitatif. Bertujuan untuk mengetahui seberapa besar pengaruh variabel promosi, harga, kepercayaan, kemudahan $\left(\mathrm{X}_{1}, \mathrm{X}_{2}, \mathrm{X}_{3}, \mathrm{X}_{4}\right)$, terhadap keputusan pembelian secara online (Y).

\section{Populasi Dan Sampel}

Dalam riset, populasi digunakan untuk mengatakan segala elemen dari sesuatu daerah yang jadi target riset ataupun merupakan totalitas dari objek riset. Populasi dalam riset ini merupakan mayarakat universal yang memanfaatkan internet aktif serta mengenali produk Kopi Andanan. (Sugiyono, 2013) 
Setelah itu dari populasi tersebut diambil sebagian sampel. sKriteria populasi yang digunakan ialah konsumen masyarakat umum pengguna internet serta mengenali usaha Kopi Andanan, minimun sempat melaksanakan ataupun membaca iklan dari Kopi Andanan. Dalam riset ini penulis melaksanakan analisis berbentuk wawancara dengan jumlah responden sebanyak 5 orang serta kuesioner sebanyak 40 responden konsumen kopi andanan (Sugiyono, 2014).

\section{Teknik Pengumpulan Data}

\section{Wawancara.}

Wawancaran untuk mengumpulkan informasai serta memperoleh data secara langsung lewat obrolan terhadap konsumen kopi andanan. Wawancara ini betabiat mengeksplor secara jelas dengan mennanyakan kepada 5 narasumber yang berkaitan dengan riset.

\section{Observasi}

Observasi di jalani untuk mengamati objek yang diteliti secara langsung maupun tak langsung untuk mendapatkan informasi yang berkaitan dengan suatu riset yang sedang di teliti.

\section{Dokumentasi}

Dokumentasi dilakukan sebagai cara untuk mengumpulkan data berupa catatan maupun foto yang berkaitan dengan penelitian.

\section{Kuesioner}

Kusioner disebarkan untuk mendapatkan informasai secara tertulis lewat penyebaran kuesioner kepada 40 responden kopi andanan secara langsung. Dengan tujuan mendapatkan informasi yang srtelah itu bisa di jalani pengujian.

\section{Teknik Analisis Data}

\section{Uji Validitas}

Mengukur level ke validan dan keaslian dalam sebuah konsep yang di teliti. Uji validitas bisa dikatakan valid jika bisa mengukur apa yang kita inginkan secara benar dan tepat.

\section{Uji Reliabilitas}


Untuk mengukur konsistensi suatu perlengkapan alat ukur, bisa di katakana reabel bila alpha cromback > 0.60 jika nilai < 0,60 maka data tidak valid (Umar, 2003).

\section{Uji Regresi}

Mengetahui seberapa besar pengaruh variabel independen terhadap variabel dependen.

\section{HASIL DAN PEMBAHASAN}

\section{Hasil}

\section{Pengujian validitas}

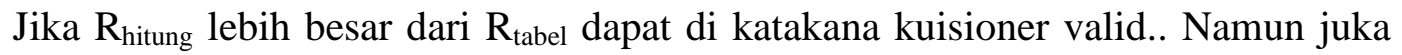
$\mathrm{R}_{\text {hitung }}<\mathrm{R}_{\text {tabel }}$ dapat di katakana kuisioner tidak valid. Pengujian ini dapat juga dilihat kelengkapannya.

Tabel 1. Hasil Uji Validitas

\begin{tabular}{|c|c|c|c|}
\hline $\begin{array}{l}\text { VARIABEL/INDIKAT } \\
\text { OR }\end{array}$ & $\mathbf{R}$ & $\mathbf{R}$ & Keterangan \\
\hline & Hitung & Tabel & \\
\hline 2 & 3 & 4 & 5 \\
\hline \multicolumn{4}{|l|}{ Produk $\times 1$} \\
\hline 1 & 0.774 & 0.312 & Valid \\
\hline 2 & 0.690 & 0.312 & Valid \\
\hline 3 & 0.709 & 0.312 & Valid \\
\hline 4 & 0.792 & 0.312 & Valid \\
\hline \multicolumn{4}{|l|}{ Produk $\times 2$} \\
\hline 1 & 0.648 & 0.312 & Valid \\
\hline 2 & 0.816 & 0.312 & Valid \\
\hline 3 & 0.679 & 0.312 & Valid \\
\hline 4 & 0.732 & 0.312 & Valid \\
\hline \multicolumn{4}{|l|}{ Produk $\times 3$} \\
\hline 1 & 0.657 & 0.312 & Valid \\
\hline 2 & 0.576 & 0.312 & Valid \\
\hline s3 & 0.799 & 0.312 & Valid \\
\hline 4 & 0.767 & 0.312 & Valid \\
\hline \multicolumn{4}{|l|}{ Produk $\times 4$} \\
\hline 1 & 0.730 & 0.312 & Valid \\
\hline 2 & 0.754 & 0.312 & Valid \\
\hline 3 & 0.588 & 0.312 & Valid \\
\hline 4 & 0.640 & 0.312 & Valid \\
\hline
\end{tabular}




\begin{tabular}{|c|c|c|c|}
\hline Produk Y & & & \\
\hline 1 & 0.469 & 0.312 & Valid \\
\hline 2 & 0.550 & 0.312 & Valid \\
\hline 3 & 0.749 & 0.312 & Valid \\
\hline 4 & 0.673 & 0.312 & Valid \\
\hline 5 & 0.669 & 0.312 & Valid \\
\hline
\end{tabular}

\section{Pengujian Reliabilitas}

Dikatakan reliabel apabila nilai Cronbach Alpha lebih dari 0.60 (CronbachAlph > 0.60) hasil yang di ringkas tiap-tiap variable berikut :

Tabel 2. Pengujian Reliabilitas

\begin{tabular}{|l|c|c|}
\hline \multicolumn{1}{|c|}{ Variabel } & Cronbac Alpha & Keterangan \\
\hline Promosi (Promotion) & 0.727 & Reliabilitas \\
\hline Harga (Price) & 0.688 & Reliabilitas \\
\hline Kepercayaan (Trust) & 0.652 & Reliabilitas \\
\hline Kemudahan (Convenience) & 0.610 & Reliabiliabilitas \\
\hline $\begin{array}{l}\text { Keputusan Pembelian secara } \\
\text { Online }\end{array}$ & 0.609 & \\
\hline
\end{tabular}

\section{Regresi Berganda}

Menguiji hipotesis tentang pengaruh secara parsial serta secara simultan variabel bebas terhadap variabel terikat. Analisis regresi digunakan untuk memprediksikan seberapa jauh pergantian nilai variabel terikat terhadap keputusan pembelian online. 
Tabel 3. Uji Regresi Berganda

\begin{tabular}{|c|c|c|c|c|c|c|}
\hline \multicolumn{7}{|c|}{ Coefficients $^{a}$} \\
\hline \multirow{2}{*}{\multicolumn{2}{|c|}{ Model }} & \multicolumn{2}{|c|}{$\begin{array}{l}\text { Unstandardized } \\
\text { Coefficients }\end{array}$} & \multirow{2}{*}{$\begin{array}{c}\text { Standardized } \\
\text { Coefficients } \\
\text { Beta }\end{array}$} & \multirow[t]{2}{*}{$T$} & \multirow[t]{2}{*}{ Sieg. } \\
\hline & & B & $\begin{array}{l}\text { Std. } \\
\text { Error }\end{array}$ & & & \\
\hline 1 & (Constant) & -0.490 & 1.609 & & -0.304 & 0.763 \\
\hline & Promosi (X1) & 0.477 & 0.074 & 0.664 & 6.438 & 0.000 \\
\hline & Harga (X2) & 0.156 & 0.077 & 0.167 & 2.032 & 0.050 \\
\hline & $\begin{array}{l}\text { Kepercayaan } \\
(\mathrm{X} 3)\end{array}$ & -0.210 & 0.96 & -0.223 & -2.203 & 0.034 \\
\hline & $\begin{array}{l}\text { Kemudahan } \\
(\times 4)\end{array}$ & 0.609 & 0.091 & 0.543 & 6.714 & 0.000 \\
\hline
\end{tabular}

Sumber : Lampiran output SPSS 2021

Uji F untuk mengetahui apakah promosi (promotion), Harga (Price), Kepercayaan (Trust), dan Kemudahan (Convidienence) secara bersama-sama berpengaruh secara signifikan terhadap keputusan pembelian online. Uji F dilakukan dengan membandingkan $\mathrm{F}_{\text {hitung }}$ dengan $\mathrm{F}_{\text {tabel }}$. Dengan table berikut:

Tabel 4. Uji Simultan (Uji F)

\begin{tabular}{|c|c|c|c|c|c|c|}
\hline \multicolumn{7}{|c|}{ ANOVA $^{a}$} \\
\hline \multicolumn{2}{|l|}{ Model } & Sum of Squares & Df & Mean Square & $\mathrm{F}$ & Sig. \\
\hline \multirow[t]{3}{*}{1} & Regression & 151.350 & 4 & 37.838 & 53.780 & $.000^{\mathrm{b}}$ \\
\hline & Residual & 24.625 & 35 & .704 & & \\
\hline & Total & 175.975 & 39 & & & \\
\hline
\end{tabular}

$\mathrm{F}_{\text {tabel }}=\mathrm{F}(\mathrm{k} ; \mathrm{n}-\mathrm{k})=\mathrm{F}(4 ; 36)=2,74$. diperoleh nilai Sig $\mathrm{F}>0.000(5 \%)$ dengan $F_{\text {hitung }} 53.780\left(F_{\text {hitung }}>F_{\text {tabel }}\right)=53.780>2,63$. Keempat variabel secara simultan berpengaruh terhadap keputusan pembelian online. 
Uji T digunakan untuk menguji membandingkan $\mathrm{t}_{\text {hitung }}$ dengan $\mathrm{t}_{\text {tabel }}$ pada tarafnya $\alpha$ $=0,05$. Uji $t$ berpengaruh signifikan jika hasil perhitungan $t_{\text {hitung }}>t_{\text {tabel }}$ atau probabilitas kesalahan $<5 \%$ (sig $<0,05)$. F tabel yang digunakan adalah $t_{\text {tabel }}=t(a / 2 ; n-k-1)=$ $\mathrm{t}(0,025 ; 35)=2,030$.

Tabel 5. Uji parsial (Uji T)

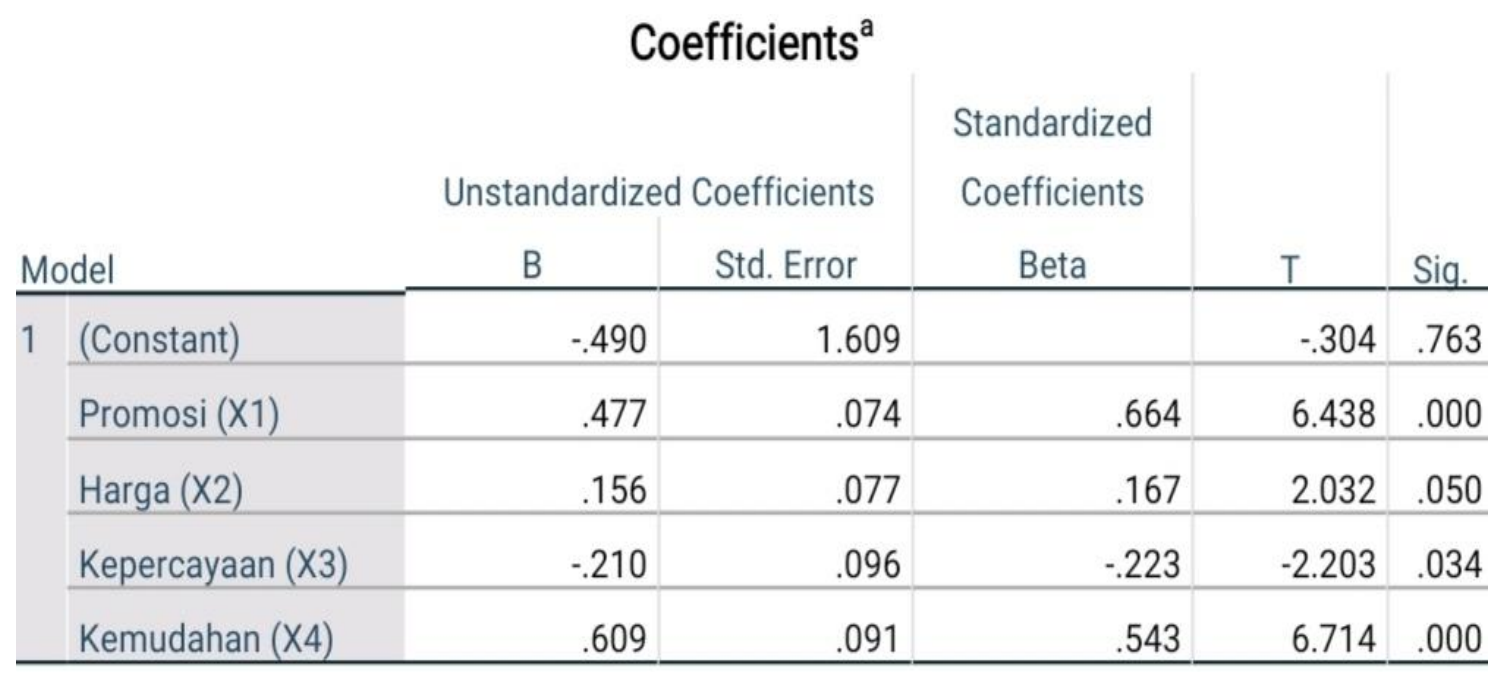

a. Dependen Variable : Keputusan Pembelian Online $(\mathrm{Y})$

\section{Pengaruh Promosi}

Variabel promosi (X1) membuktikan $\mathrm{t}_{\text {hitung }}>\mathrm{t}_{\text {tabel }}(6.438>2,030)$, atau sig $<\alpha$ $(0,000<0,05)$, sehingga variabel promosi (X1) berpengaruh terhadap keputusan pembelian online kopi andanan, Kota Bandar Lampung.

2. Pengaruh Harga

Variabel Harga (X2) membuktikan nilai $t_{\text {hitung }}>t_{\text {tabel }}(2.032>2,030)$, atau sig $=\alpha(0,050=0,05)$, sehingga variabel promosi $(\mathrm{X} 2)$ masih berpengaruh terhadap keputusan pembelian secara online kopi andanan, Kota Bandar Lampung.

3. Pengaruh Kepercayaan

Variabel promosi (X3) membuktikan nilai $\mathrm{t}_{\text {hitung }}<\mathrm{t}_{\text {tabel }}(-2,203<2,030)$, atau sig $<\alpha(0,034<0,05)$, berarti variabel keprcayaan (X3) berpengaruh terhadap keputusan pembelian secara online kopi andanan, Kota Bandar Lampung.

4. Pengaruh Kemudahan 
Variabel kemudahan $(\mathrm{X} 4)$ membuktikan nilai $\mathrm{t}_{\text {hitung }}>\mathrm{t}_{\text {tabel }}(6.714>2,030)$, atau sig $<\alpha(0,000<0,05)$ sehingga variabel promosi $(\mathrm{X} 4)$ berpengaruh terhadap keputusan pembelian online kopi andanan, Kota Bandar Lampung.

Koefisien determinasi ialah besaran yang membuktikan besarnya variabel- variabel dependen. Ditetetapkan dengan nilai adjusted Rsquere sebagaimana bisa dilihat pada table berikut :

Tabel 6. Uji koefisien determinasi

\begin{tabular}{l|r|r|r|r}
\multicolumn{1}{c}{} & \multicolumn{2}{c}{ Model Summary } \\
Model & $\mathrm{R}$ & $\mathrm{R}$ Square & Adjusted R Square & \multicolumn{2}{c}{$\begin{array}{c}\text { Std. Error of the } \\
\text { Estimate }\end{array}$} \\
\hline 1 & $.927^{\mathrm{a}}$ & .860 & .844 & .839 \\
\hline
\end{tabular}

a. Predictors : (Constant), Kemudahan (X4), Kepercayaan (X3), Harga (X2), Promosi (X1) Sumber: SPSS 2021

Nilai adjusted R squere 0, 860. Berarti seluruh variabel memiliki konstribusi secara bersama-sama $86 \%$ terhadap variabel terikat, sisanya $14 \%$ dipaparkan oleh factor lain diluar dari riset ini.

\section{Pembahasan}

Memandang realitas pertumbuhan ekonomi, hingga tuntutan yang mempengaruhi konsumen dalam belanja terus menjadi bermacam- macam serta terus menerus tumbuh cocok dengan pergantian era. Didalam hidupnya manusia mempunyai bermacam kebuutuhan, mulai dari kebutuhan dasar hingga tingkatan kebutuhan yang lebih besar. Salah satu kebutuhan manusia merupakan agar bisa menikmati secangkir kopi yang mempunyai cita rasa yang khas.

\section{Pengaruh Promosi (Promotion)}

Bersumber pada hasil uji $\mathrm{T}$ promosi membuktikan nilai $\mathrm{t}_{\text {hitung }}>\mathrm{t}_{\text {tabel }}(6.438>$ $2,030)$, nilai $\operatorname{sig}>\alpha(0,000>0,05)$. variabel promotion $(\mathrm{X} 1)$ mempengaruhi keputusan pembelian online. Hingga bisa disimpulkan hipotesis diterima. Perihal ini diakibatkan sebab konsumen mengenali toko kopi andanan serta memandang terdapatnya tawaran harga yang di tawarkan tersebut. 


\section{Pengaruh Harga (Price)}

Bersumber pada hasil uji $\mathrm{T}$ harga membuktikan nilai $\mathrm{t}_{\text {hitung }}>\mathrm{t}_{\text {tabel }}(2.032>2,030)$, dan nilai sig $=\alpha(0,050=0,05)$, berarti variable price $(\mathrm{X} 2)$ mempengaruhi keputusan pembelian online. Hingga bisa disimpulkan bahwa hipotesis diterima.

\section{Pengaruh Kepercayaan (Trust)}

Bersumber pada hasil uji $\mathrm{T}$, variabel kepercayaan membuktikan nilai $\mathrm{t}_{\text {hitung }}>$ $t_{\text {tabel }}(-2,203<2,030)$, sedangkan nilai sig $<\alpha(0,034<0,05)$, yang berarti variable Trust (X3) berpengaruh terhadap keputusan pembelian online. Hingga bisa disimpulkan kalau hipotesis diterima. Perihal ini diakibatkan sebab pintarnya managemen kopi andanan mempromosikan produknya buat meyakinkan konsumen supaya membeli produknya.

\section{Pengaruh kemudahan (Convienence)}

Bersumber pada hasil uji $\mathrm{T}$, variabel kemudahan membuktikan nilai $\mathrm{t}_{\text {hitung }}>\mathrm{t}_{\text {tabel }}$ (6.714 > 2,030), atau sig $<\alpha(0,000<0,05)$. yang berarti variabel Convienence (X4) berpengaruh terhadap keputusan pembelian online. Hingga bisa disimpulkan kalau hipotesis diterima. Perihal ini diakibatkan biarpun industri kopi andanan masih terbilang baru hendak namun managemen kopi telah menawarkan kemudahan proses pembelian kepada konsumen.

\section{PENUTUP}

\section{Kesimpulan}

1. Factor promosi(promotion), harga(price), kepercayaan(trust), serta kemudahan( convienence) berpengaruh terhadap keputusan pembelian secara online. Keunggulan berbelanja online merupakan gampang serta praktisnya produk hingga samapai ke konsumen.

2. Factor yang mempengaruhi secara parsial ialah promosi( promotion), harga(price), kemudahan(covienence), sebaliknya buat kepercayaan(trust), masih dapat mempengaruhi keputusan pembelian online( konsumen kopi andanan kota Bandar Lampung)

3. Factor yang sangat dominan berpengaruh adalah Kemudahan. Sebab produk yang di idamkan serta diperlukan konsumen sangat gampang proses pembeliannya. 


\section{Saran}

Disarankan untuk penjualan agar membuat varian produk dengan bergabagai varian serta kemasan bubuk kopi untuk konsumen. Dalam pemasaran lewat internet, pengusaha butuh memperhatikan dari seluruh sisi serta dikombinasikan. Sebab seluruh factor yang pengaruhi keputusan pembelian secara online berarti. Sehingga pembelian bisa bertambah. Keyakinan ialah kunci kala konsumen hendak membeli produk online. Industri butuh membagikan stimulus yang bisa menambah keyakinan konsumen secara terus menerus. 